Article

\title{
Adaptive Filtering-Based Pseudo Open-Loop Three-Phase Grid-Synchronization Technique
}

\author{
Hafiz Ahmed 1(D), Samet Biricik ${ }^{2,3}\left(\mathbb{D}\right.$, Elhoussin Elbouchikhi $\left.{ }^{4, *} \mathbb{(}\right)$ and Mohamed Benbouzid ${ }^{5,6}(\mathbb{D}$ \\ 1 School of Mechanical, Aerospace and Automotive Engineering, The Futures Institute, Coventry University, \\ Coventry CV1 2TL, UK; hafiz.h.ahmed@ieee.org \\ 2 Department of Electrical and Electronics Engineering, European University of Lefke, Lefke, \\ Northern Cyprus, TR-10 Mersin, Turkey; sbiricik@eul.edu.tr \\ 3 School of Electrical and Electronic Engineering, Technological University Dublin, Dublin D24 FKT9, Ireland \\ 4 ISEN Yncréa Ouest, UMR CNRS 6027 IRDL, 29200 Brest, France \\ 5 UMR CNRS 6027 IRDL, University of Brest, 29238 Brest, France; Mohamed.Benbouzid@univ-brest.fr \\ 6 Logistics Engineering College, Shanghai Maritime University, Shanghai 201306, China \\ * Correspondence: elhoussin.elbouchikhi@isen-ouest.yncrea.fr
}

Received: 7 May 2020; Accepted: 3 June 2020; Published: 7 June 2020

\begin{abstract}
This paper studies the grid-synchronization problem of three-phase system. Second-order adaptive filters are a popular tool for grid-synchronization. In this context, reduced-order generalized integrator has attracted some attention in recent time. However, existing implementations cannot control directly the closed-loop poles (real and imaginary) of reduced-order generalized integrator. To overcome this limitation, this paper proposes a novel reduced-order generalized integrator structure. To make the proposed technique frequency adaptive, an open-loop frequency estimation technique is also used. Comparative performance analysis are provided over two other advanced and recently proposed techniques. Results demonstrate the suitability and effectiveness of the proposed technique.
\end{abstract}

Keywords: grid-synchronization; phase estimation; frequency estimation; adaptive filter

\section{Introduction}

The Paris Agreement set an ambitious target of net-zero carbon emissions by 2050 . Innovative technological solutions are required to achieve this challenging target. In this context, renewable energy sources (RES) are going to play a major role. RES are generally connected to the grid trough grid-connected converter (GCC) [1-8]. In addition, GCC are also used in numerous other power and energy systems application, e.g., AC/DC rectifier [9-11], dynamic voltage restorer [12,13], active power filter [14,15], to name a few. All these applications require the frequency and phase information of the grid voltage signal for grid-synchronized operation of the GCC. This highlights the importance of estimating the frequency and phase of the grid voltage signal.

Grid-synchronization is a mature topic and numerous results are already proposed in the literature. Some popular techniques are: discrete Fourier transformation (DFT) [16,17], gradient techniques [18-20], demodulation techniques [21,22], maximum likelihood estimator [23], Phase-locked loop (PLL) [24-28], adaptive observers [29-31], self-tuning filter [32,33], Kalman filtering [34,35], second-order adaptive filter [36-43], open-loop techniques [44-46].

Gradient techniques [18-20] estimate the parameters of the grid voltage by considering a cost-function. Typically, the square of the estimation error is considered to be the cost-function. The the gradient estimator is found by minimizing this cost-function. Gradient estimators are typically computationally expensive as the estimators require complex matrix manipulation. Moreover, tuning the weights of gradient estimators are not straightforward. The maximum likelihood 
estimator [23] also uses a cost-function to estimate the unknown frequency; however, from a statistical point of view. Frequency domain approaches e.g., DFT [16,17] exploits the periodic nature of the grid voltage signal. DFT has large memory requirement in off-nominal frequency condition and in the presence of harmonics. This can limit the implementation in low-cost micro-controllers.

Demodulation [21,22] is inspired by the communication application where phase-angle needs to be extracted from the measured signal. Demodulation has very good performance. However, demodulation uses trigonometric functions and real-time implementation of trigonometric functions are computationally expensive. Approximation of the trigonometric functions can be used; however, this comes at the cost of accuracy. Adaptive observer [29-31] considers a parameterized linear model of the grid voltage signal where unknown frequency is the parameter. Then by using Lyapunov stability theory, an adaptive law for the unknown frequency estimation is derived. Adaptive observers are sensitive to unmodeled disturbances and the performance may degrade significantly. Kalman filter [34] uses similar model as the adaptive observer. Kalman filter minimizes the effect of process and measurement noises by adaptively changing the filter gain. Kalman filter has numerous parameters to tune and the tuning process can be complex. Moreover, the order of Kalman filter is two times than that of the adaptive observer.

PLL is another technique that got significant attention in the literature. PLL is widely used in industry and academia. Using Park transformation [47], PLL estimates the unknown frequency by using a proportional-integral type low-pass filter (LPF). Performance of the PLL heavily depends of the LPF tuning. As such, fast dynamic response cannot be obtained without comprising the accuracy. PLL can be implemented using second-order adaptive filters [36-40] also. Second-order adaptive filters are also used in frequency-locked loop (FLL). Out of various second-order adaptive filters, second-order generalized integrator (SOGI) and adaptive notch filter (ANF) are two popular techniques. Using the model of linear harmonic oscillators, SOGI and ANF can accurately extract the fundamental component of the grid voltage signal.

In the three-phase setting, reduced-order generalized integrator (ROGI) [48] mimics SOGI. SOGI is a second-order band-pass filter while ROGI is a first-order complex band-pass filter. ROGI has excellent performance; however, existing implementations of ROGI cannot directly control the closed-loop poles of ROGI. By controlling the closed-loop poles, convergence speed of ROGI can be made arbitrary according to user choice. The self-tuning filter [32,33] is similar to ROGI; however, it does not use frequency feedback. All the techniques reviewed so far are closed-loop techniques. Open-loop techniques [44-46] do not use any direct feedback in frequency estimation. This can provide absolute stability as opposed to closed-loop techniques.

In this paper, we are considering a quasi open-loop grid-synchronization technique by employing ROGI-type adaptive filter. For this purpose, we propose a novel ROGI structure where the closed-loop poles of ROGI can be tuned according to user choice. This is a significant advantage of the proposed technique over the existing literature as arbitrary pole placement allows to tune the dynamic response according to user's choice. This is very important for applications where fast dynamic response is required. Moreover, open-loop frequency estimation can take benefit from the unconditional stability property of the open-loop approaches. In summary, fast dynamic response together with unconditionally stable frequency estimation are the main contributions of this paper.

The rest of this paper is organized as follows: Section 2 describes an overview of ROGI and also presents the proposed solution. Numerical simulation and experimental results are given in Section 3. Finally, Section 4 concludes this paper. 


\section{Reduced Order-Generalized Integrator: Brief Overview and Proposed Solution}

\subsection{Standard Reduced Order-Generalized Integrator}

Balanced three-phase grid voltage signals are given by:

$$
\begin{aligned}
& V_{a}=V \cos (\underbrace{\omega t+\phi}_{\theta}), \\
& V_{b}=V \cos \left(\theta-\frac{2 \pi}{3}\right), \\
& V_{c}=V \cos \left(\theta+\frac{2 \pi}{3}\right),
\end{aligned}
$$

where the amplitude, angular frequency, initial phase and instantaneous phase are denoted by $V, \omega, \phi$, and $\theta$, respectively. Three-phase voltages in Equations (1)-(3) can be transformed into the stationary reference frame by the following Clark transformation:

$$
\left[\begin{array}{l}
V_{\alpha} \\
V_{\beta}
\end{array}\right]=\frac{2}{3}\left[\begin{array}{ccc}
1 & -\frac{1}{2} & -\frac{1}{2} \\
0 & \frac{\sqrt{3}}{2} & -\frac{\sqrt{3}}{2}
\end{array}\right]\left[\begin{array}{l}
V_{a} \\
V_{b} \\
V_{c}
\end{array}\right]
$$

Clarke transformed voltages are given as:

$$
\begin{aligned}
& V_{\alpha}=V \cos (\omega t+\phi) \\
& V_{\beta}=V \sin (\omega t+\phi)
\end{aligned}
$$

For the grid voltage (5) and (6), inspired by second-order generalized integrator [49], the following estimator can be designed:

$$
\begin{aligned}
& \dot{\hat{V}}_{\alpha}=-\hat{V}_{\beta} \hat{\omega}+\Lambda\left(V_{\alpha}-\hat{V}_{\alpha}\right) \\
& \dot{\hat{V}}_{\beta}=\hat{V}_{\alpha} \hat{\omega}+\Lambda\left(V_{\beta}-\hat{V}_{\beta}\right)
\end{aligned}
$$

where^represents estimated value and $\Lambda>0$ is the filter gain. Transfer function of the estimator (7) and (8) in the state vector notation is given by:

$$
\frac{\hat{V}_{\alpha}(s)+j \hat{V}_{\beta}(s)}{V_{\alpha}(s)+j V_{\beta}(s)}=G_{\alpha \beta}(s)=\frac{\Lambda}{s-j \hat{\omega}+\Lambda}
$$

Transfer function (9) shows that the estimator (7) and (8) is a complex band-pass filter (CBF) of first-order. Standard SOGI is a real band-pass filter (BPF) of second-order. This is why the estimator (7) and (8) is known as reduced-order generalized integrator in the literature [48]. Eigenvalues of the standard ROGI are $-\Lambda \pm j \hat{\omega}$. From the eigenvalues, it is clear that only the real-part is tunable while the imaginary part remains constant.

\subsection{Enhanced Reduced Order-Generalized Integrator}

Standard ROGI as described in Section 2.1 uses only direct feedback of the estimation error. This does not allow manipulating the imaginary part of the closed-loop system eigenvalues. In addition to direct feedback, cross feedback can be used to overcome this limitation. This idea will be considered 
in this section. Before introducing the proposed solution, let us consider the desired closed-loop poles to be $\hat{\omega}\left(\lambda_{1} \pm i \lambda_{2}\right)$. Then the dynamics of the proposed enhanced ROGI (EROGI) are given below:

$$
\begin{aligned}
& \dot{\hat{V}}_{\alpha}=-\hat{V}_{\beta} \hat{\omega}+\lambda_{1}\left(V_{\alpha}-\hat{V}_{\alpha}\right) \hat{\omega}-\left(1+\lambda_{2}\right)\left(V_{\beta}-\hat{V}_{\beta}\right) \hat{\omega} \\
& \dot{\hat{V}}_{\alpha}=\hat{V}_{\alpha} \hat{\omega}+\left(1+\lambda_{2}\right)\left(V_{\alpha}-\hat{V}_{\alpha}\right) \hat{\omega}+\lambda_{1}\left(V_{\beta}-\hat{V}_{\beta}\right) \hat{\omega}
\end{aligned}
$$

The transfer function of EROGI in the state vector notation is given by:

$$
\frac{\hat{V}_{\alpha}(s)+j \hat{V}_{\beta}(s)}{V_{\alpha}(s)+j V_{\beta}(s)}=G_{\alpha \beta}(s)=\frac{\lambda_{1}+j \lambda_{2}}{s-j \hat{\omega}+\lambda_{1}+j \lambda_{2}}
$$

Eigenvalues of the EROGI are $\hat{\omega}\left(\lambda_{1} \pm j \lambda_{2}\right)$. Unlike ROGI, closed-loop poles of the proposed EROGI can be controlled by the user. This enhances the dynamic tuning range of the standard ROGI. Moreover, if we set the parameters of the proposed EROGI as $\lambda_{1}=\Lambda / \hat{\omega}$ and $\lambda_{2}=0$, then the standard ROGI can be obtained. As such standard ROGI can be considered as a special case of the EROGI. Frequency response of the proposed EROGI is given in Figure 1. This figure shows that EROGI behaves as a band-pass filter similar to ROGI and the frequency selectivity is determined by the closed-loop poles. Slower pole locations imply high selectivity and slow dynamic response and fast pole location implies the opposite. Therefore, the closed-loop poles can be chosen according to design requirements.

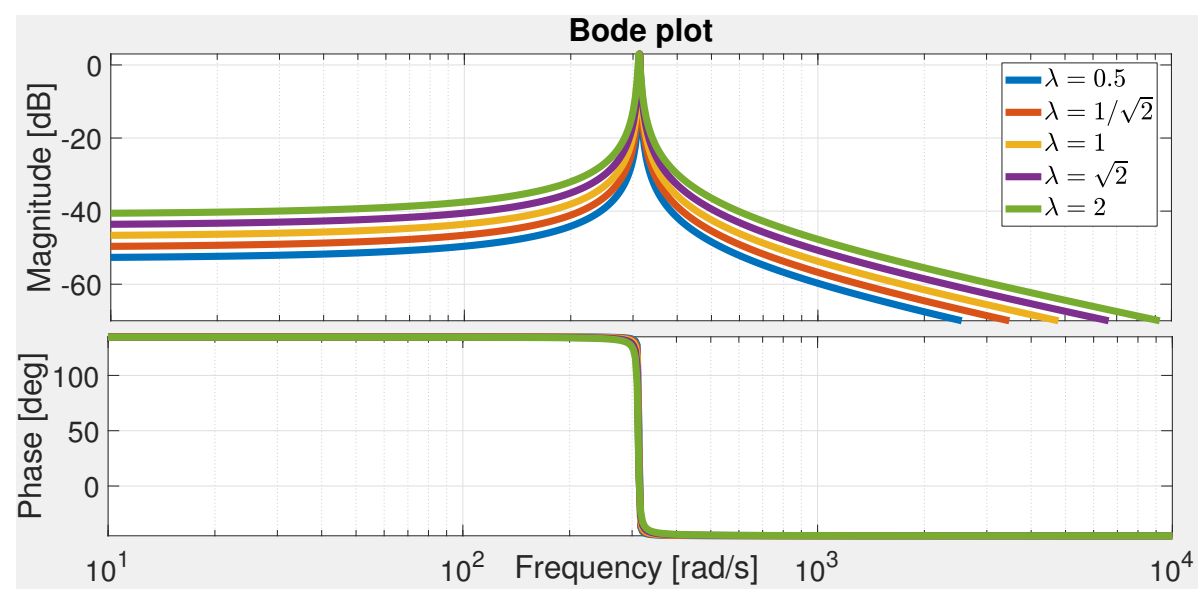

Figure 1. Frequency response of the proposed enhanced reduced-order generalized integrator for various closed-loop poles. Legends indicate the value of $\lambda$ with $\lambda=\lambda_{1}=\lambda_{2}$.

To analyze the dynamic performance of the proposed EROGI, let us consider the following individual transfer functions:

$$
\begin{aligned}
& \hat{V}_{\alpha}(s)=\frac{\eta_{1} V_{\alpha}(s)}{\left(s+\lambda_{1} \hat{\omega}\right)^{2}+\lambda_{2}^{2} \hat{\omega}^{2}}-\frac{\eta_{2} V_{\beta}(s)}{\left(s+\lambda_{1} \hat{\omega}\right)^{2}+\lambda_{2}^{2} \hat{\omega}^{2}} \\
& \hat{V}_{\beta}(s)=\frac{\eta_{2} V_{\alpha}(s)}{\left(s+\lambda_{1} \hat{\omega}\right)^{2}+\lambda_{2}^{2} \hat{\omega}^{2}}+\frac{\eta_{1} V_{\beta}(s)}{\left(s+\lambda_{1} \hat{\omega}\right)^{2}+\lambda_{2}^{2} \hat{\omega}^{2}}
\end{aligned}
$$

where $\eta_{1}=\hat{\omega}\left(s \lambda_{1}+\hat{\omega} \lambda_{1}^{2}+\hat{\omega} \lambda_{2}^{2}+\hat{\omega} \lambda_{2}\right)$ and $\eta_{2}=\hat{\omega}\left(s\left(1+\lambda_{2}\right)+\lambda_{1} \hat{\omega}\right)$. By plugging the Laplace transformation of $V_{\alpha}$ and $V_{\beta}$ in Equations (13) and (14) and taking the inverse Laplace transformation, one can find the time-domain solution of Equations (13) and (14) and are given below:

$$
\begin{aligned}
& \hat{V}_{\alpha}(t)=V_{\alpha}(t)-V \mathrm{e}^{-\lambda_{1} \omega t} \cos \left(\lambda_{2} \omega t-\phi\right) \\
& \hat{V}_{\beta}(t)=V_{\beta}(t)+V \mathrm{e}^{-\lambda_{1} \omega t} \sin \left(\lambda_{2} \omega t-\phi\right)
\end{aligned}
$$


From Equations (15) and (16), one can see that the proposed EROGI has asymptotic convergence as the second term in Equations (15) and (16) converge to zero as time goes to infinity. Block diagram of the EROGI is given in Figure 2.

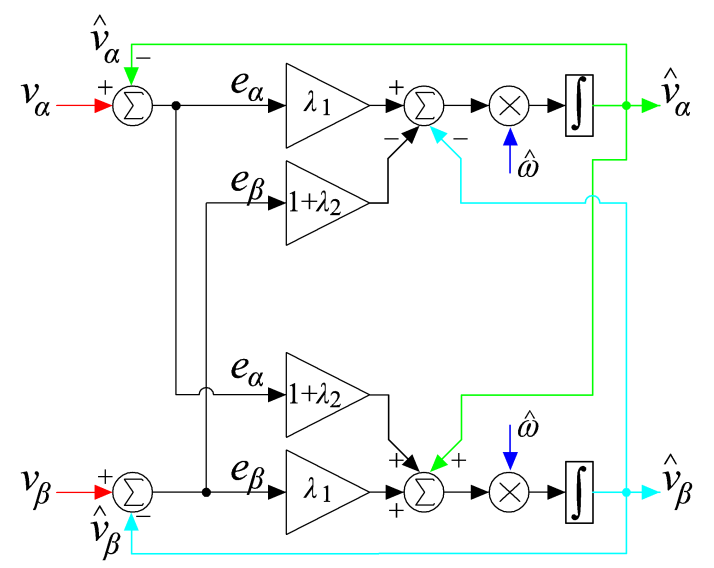

Figure 2. Block diagram of the proposed enhanced reduced-order generalized integrator.

\subsection{Frequency Estimation}

The proposed EROGI requires the estimate of the grid frequency for successful operation. Numerous techniques are available in the literature to estimate the frequency from the filtered signals $\hat{V}_{\alpha}$ and $\hat{V}_{\beta}$. In this section, we will consider an open-loop approach for the frequency estimation without using any PLL and/or FLL. An advantage of the open-loop approach is that the stability is unconditional. Moreover, no tuning is required, leading to design simplification. As the grid amplitude may vary a lot, to overcome this issue, first amplitude normalization will be considered. The normalized signals are given by:

$$
\hat{V}_{\alpha / \beta}^{n}=\frac{\hat{V}_{\alpha / \beta}}{\sqrt{\hat{V}_{\alpha}^{2}+\hat{V}_{\beta}^{2}}}
$$

where the superscript $n$ indicates normalized value and the subscript $\alpha / \beta$ indicate the signal to be either $\alpha$ signal or the $\beta$ signal. From the normalized signals, the frequency can be estimated by using any of the following two formulas:

$$
\begin{aligned}
& \hat{\omega}=\frac{\hat{V}_{\alpha}^{n} \frac{d}{d t}\left(\hat{V}_{\beta}^{n}\right)-\hat{V}_{\beta}^{n \frac{d}{d t}}\left(\hat{V}_{\alpha}^{n}\right)}{\left(\hat{V}_{\alpha}^{n}\right)^{2}+\left(\hat{V}_{\beta}^{n}\right)^{2}} \\
& \hat{\omega}=\sqrt{\left\{\frac{d}{d t}\left(\hat{V}_{\alpha}^{n}\right)\right\}^{2}+\left\{\frac{d}{d t}\left(\hat{V}_{\beta}^{n}\right)\right\}^{2}}
\end{aligned}
$$

Frequency estimated through Equations (18) and (19) may show some oscillation at the transient period due to the involved differentiation operations. To get a smooth output, a simple lead-lag filter can be used and the transfer function is given below:

$$
H(s)=\frac{\kappa s+1 / T}{s+1 / T}
$$

where $T=2 \pi / \omega_{n}$ is the nominal period of the grid voltage signal and $\kappa>0$ is a scaling factor. An alternative solution to the lead-lag filter could be the application of a moving average filter (MAF) with window length $T_{w}=T / 2$. An advantage of MAF is that in addition to smooth frequency 
estimation, it will enhance the harmonics rejection capability. Block diagram of the frequency estimation technique using Equations (19) and (20) is given in Figure 3.

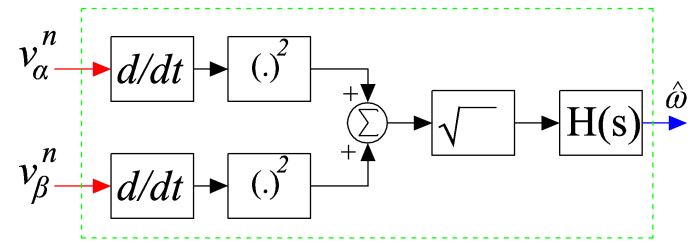

Figure 3. Block diagram of the considered frequency estimation technique.

\section{Results and Discussion}

Comparative numerical simulation and experimental studies are considered in this section to test the performance of the proposed enhanced ROGI-based pseudo open-loop grid-synchronization technique. For this purpose, SRF-PLL [47] and self-tuning filter-based pseudo-open loop (POL) grid-synchronization technique [46] are considered to be comparative techniques. For the proposed approach, the desired closed-loop poles have been selected as $-(1 / \sqrt{2}) \omega_{n}(1 \pm 1 i)$ with $\omega_{n}=100 \pi$. This corresponds to $\lambda_{1}=\lambda_{2}=1 / \sqrt{2}$ for the proposed technique. For POL, parameter of the self-tuning filter is selected as: $\lambda=50$ [46]. Loop filter parameters of SRF-PLL are selected as: $k_{p}=4 / t_{s}$ and $k_{i}=k_{p}^{2} / 4 \zeta^{2}$ where $t_{s}$ is the settling time and $\zeta$ is the damping ratio. By selecting $t_{s}=0.06 \mathrm{~s}$ ( 3 cycles) and $\zeta=1 / \sqrt{2}$, parameters are found as: $k_{p}=66.66$ and $k_{i}=2222$. All the techniques have been implemented in Matlab/Simulink. The trapezoidal method is used for discretization with a sampling period of $10^{-4} \mathrm{~s}$.

\subsection{Numerical Simulation Results}

To test the performance of the comparative techniques, four tests have been considered. They are:

- $\quad$ Test-I: $+2 \mathrm{~Hz}$ frequency jump

- $\quad$ Test-II: Simultaneous -0.5 p.u. amplitude and $60^{\circ}$ phase jumps

- $\quad$ Test-III: Harmonics robustness test

- Test-IV: Unbalance test

Numerical simulation results for Test-I are given in Figure 4. Test results show that the proposed technique has considerably fast convergence compared to SRF-PLL and POL. In terms of frequency estimation, the proposed technique has converged in $\approx 2.25$ cycles whereas POL and SRF-PLL took roughly 4 cycles. The proposed technique demonstrated a first-order response without any overshoot whereas the other techniques have second-order response with peak overshoot. Similar results can be observed for phase estimation error results also. The proposed technique has a peak overshoot of $\approx 3^{\circ}$ while it is at least two times more for the other techniques.

Simultaneous amplitude and phase jumps present a challenging scenario for grid-connected converters. This situation is considered in Test-II. Numerical simulation results for Test-II are given in Figure 5. Numerical simulation results show that despite simultaneous jumps in amplitude and phase, the proposed technique converged very fast in 3 cycles while the other two techniques are significantly slower than the proposed technique. This demonstrates the suitability of the proposed technique to provide low voltage ride through (LVRT) capability inside grid-connected converters control block.

Harmonics present significant challenge to any grid-synchronization technique. Test-III considers heavily distorted grid voltage signal. The distorted grid voltage signal is composed of $2.8 \%-5$ th, $1.4 \%-7$ th, $2.3 \%-9$ th, $1.5 \%-11$ th order harmonics, $1.1 \%-30 \mathrm{~Hz}$ sub-harmonics, and $1.3 \%-180 \mathrm{~Hz}$ inter-harmonics. Numerical simulation results for Test-III are given in Figure 6. Simulation results show that the proposed technique has the lowest ripple in the estimated frequency. Moreover, the filtered unity sine signal's 
show that the proposed technique has excellent filtering capability. This is very useful in generating the reference current for the current control of grid-connected converters.

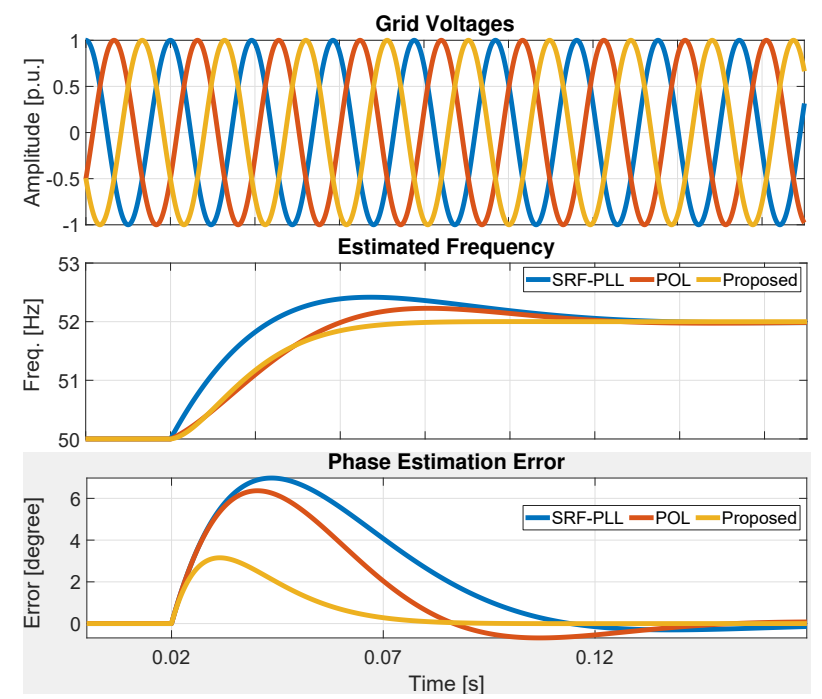

Figure 4. Comparative numerical simulation results for Test-I: $+2 \mathrm{~Hz}$ step change in frequency.
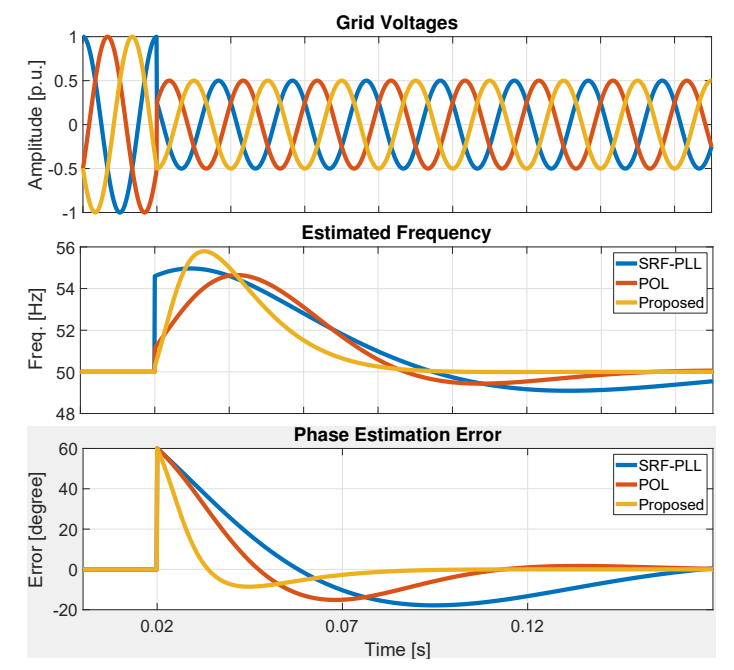

Figure 5. Comparative numerical simulation results for Test-III: Simultaneous -0.5 p.u.amplitude and $60^{\circ}$ phase jump.

Voltage unbalance is another challenging condition for any three-phase grid-synchronization technique. To test the performance of the comparative techniques, Test-IV considers voltage unbalance. Initially, the grid voltage is comprised of only positive sequence component i.e., $1 \angle 0^{\circ}$. After the fault, the grid voltage is comprised of $0.75 \angle 45^{\circ}$ positive sequence and $0.25 \angle 0^{\circ}$ negative sequence components. Numerical simulation results for Test-IV are given in Figure 7. Simulation results show that all the techniques are very quick to react to the change in grid voltages. As all the techniques are designed considering balanced grid, estimation ripple is unavoidable. However, from the estimated frequencies in Figure 7, it can be seen that the proposed technique has the lowest steady state ripple value. Moreover, the phase estimation error for the proposed technique also converged significantly faster than the comparative techniques. 

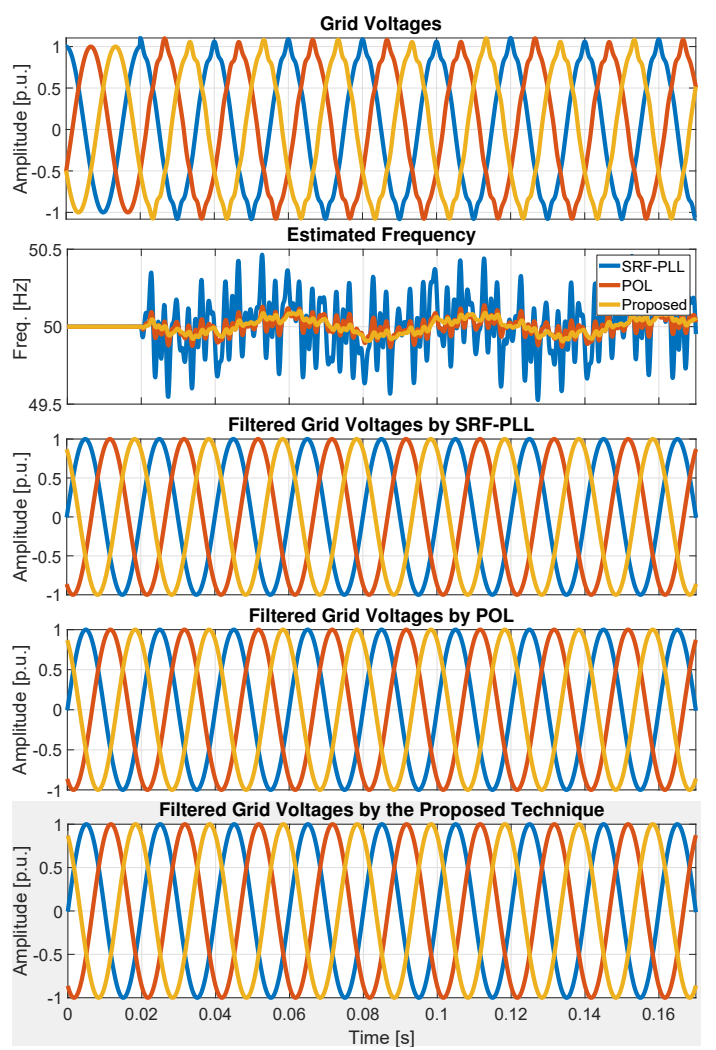

Figure 6. Comparative numerical simulation results for Test-III: Harmonics robustness test.
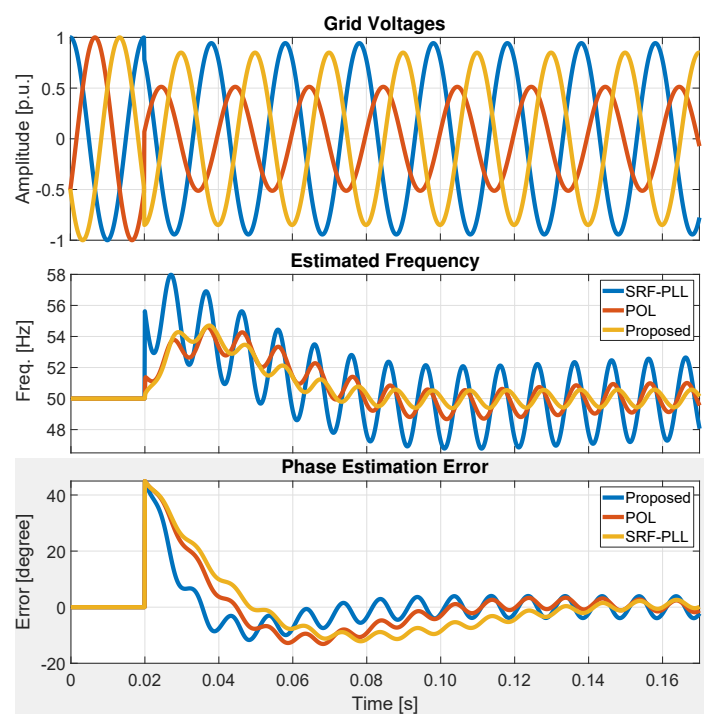

Figure 7. Comparative numerical simulation results for Test-IV: Unbalance test.

\subsection{Experimental Validation}

Block diagram of the experimental setup is given in Figure 8 while the setup is shown in Figure 9. Experimental setup used for the validation is given in Figure 8. To emulate the grid voltages, a DC motor is coupled to a synchronous machine. The generated voltages are measured at the load side using LEM LV25-P voltage sensors. Measurements from the sensors are fed back to a Texas Instruments TMS320F28335 microcontroller for real-time calculation. The comparative techniques are implemented in Matlab/Simulink and code generation was used to embed them into the TMS320F28335 microcontroller. 


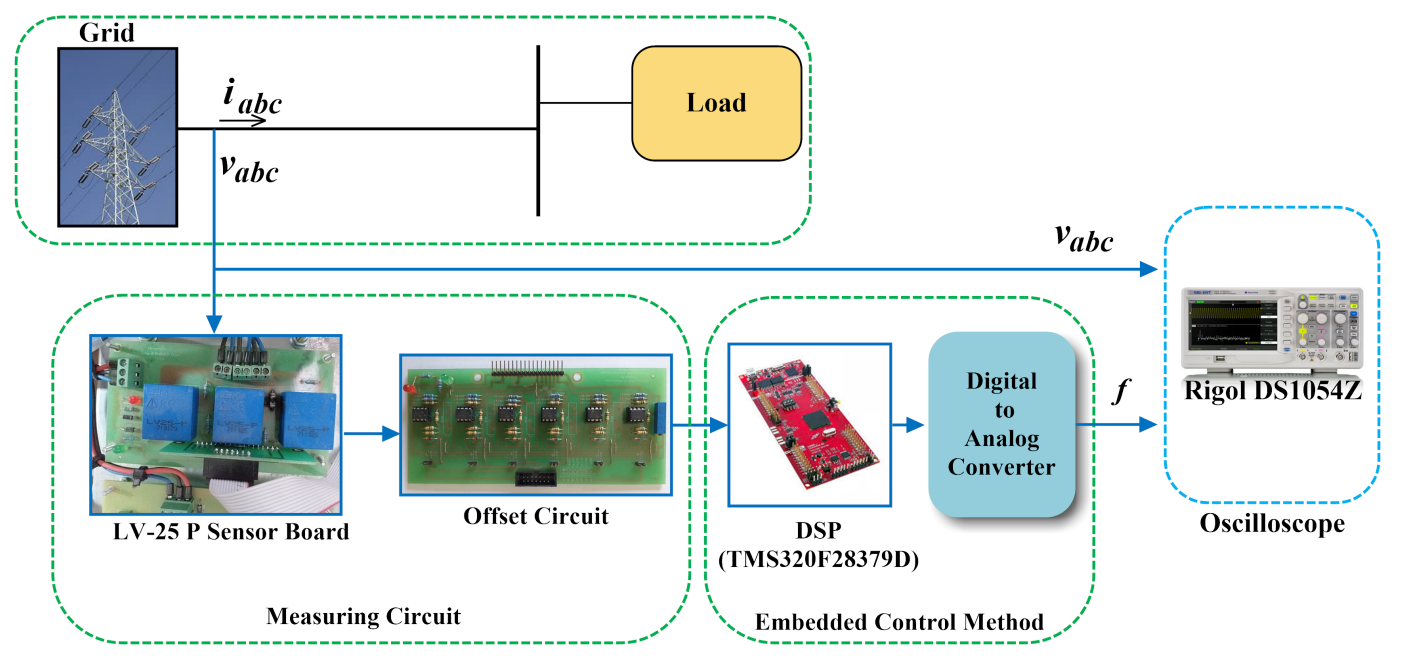

Figure 8. Block diagram of the experimental setup.

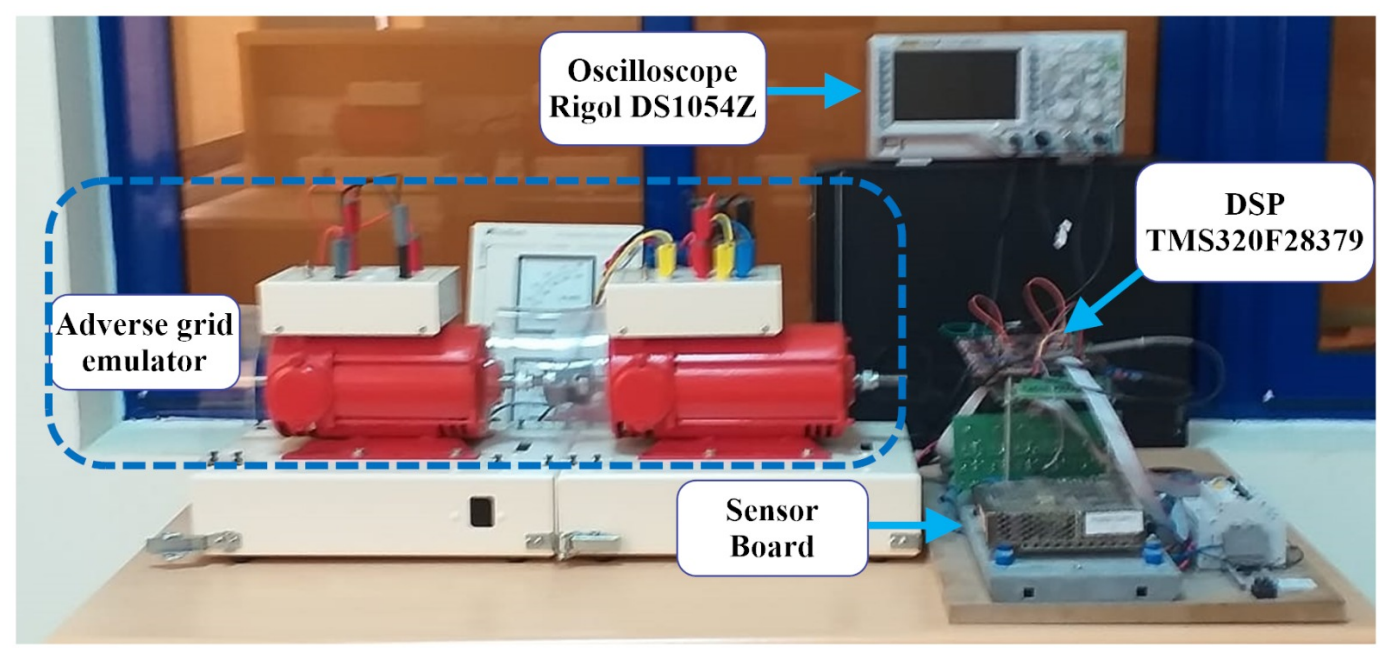

Figure 9. Setup for experimental validation.

In the first test, $-2 \mathrm{~Hz}$ frequency step is considered. Experimental results are given in Figure 10. Very fast responses can be observed when a frequency change is detected. However, the proposed technique is quicker than the others. One point to be noted here is that in simulation, the grid frequency can be changed arbitrarily without changing the phase and/or amplitude. However, in experimental implementation, such kind of change is extremely difficult to obtain. Often the change in frequency comes with change in amplitude and/or phase. For example, in Figure 10c, to reduce the frequency, the generator speed is suddenly reduced. This may have caused the sudden change in the voltage after the frequency in Figure 10c. This largely attributes to the difference in convergence time for the different techniques. Similar to simulation results, the proposed technique is also very suitable in practice to track time-varying grid frequency.

In the second test, -0.5 p.u. voltage sag is considered. Experimental results are given in Figure 11. These figures show that the comparative techniques are not very sensitive to any change in the signal amplitude. Zoomed view show that out of the three techniques, the frequency estimated by the proposed technique demonstrated the lowest sensitivity to the voltage sag. This shows that the proposed technique is suitable for practical implementation even in the presence of large voltage sag. 


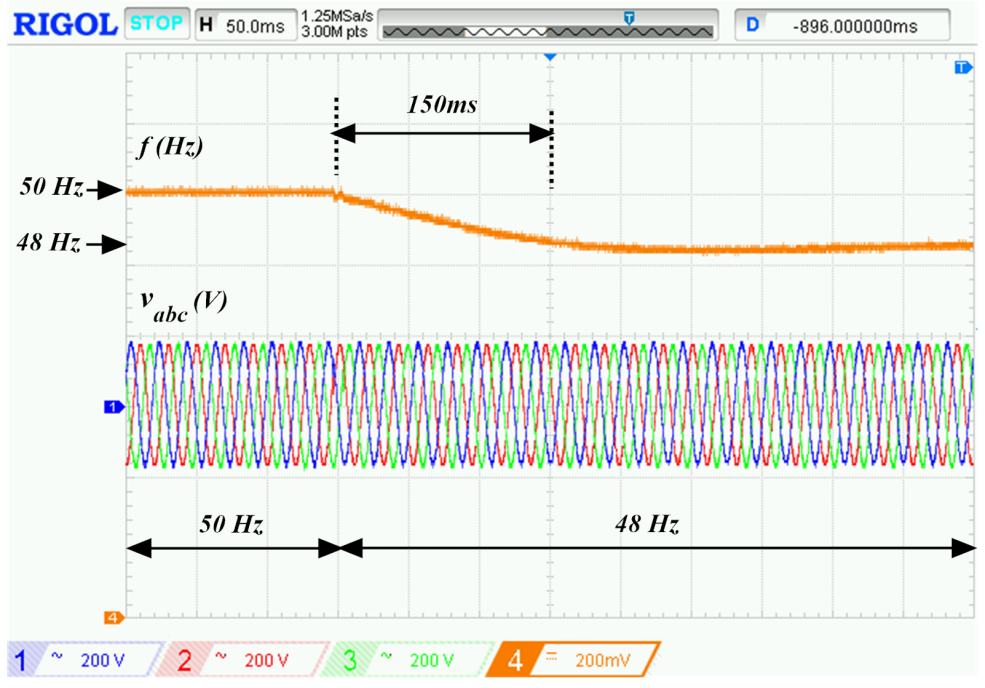

(a) POL

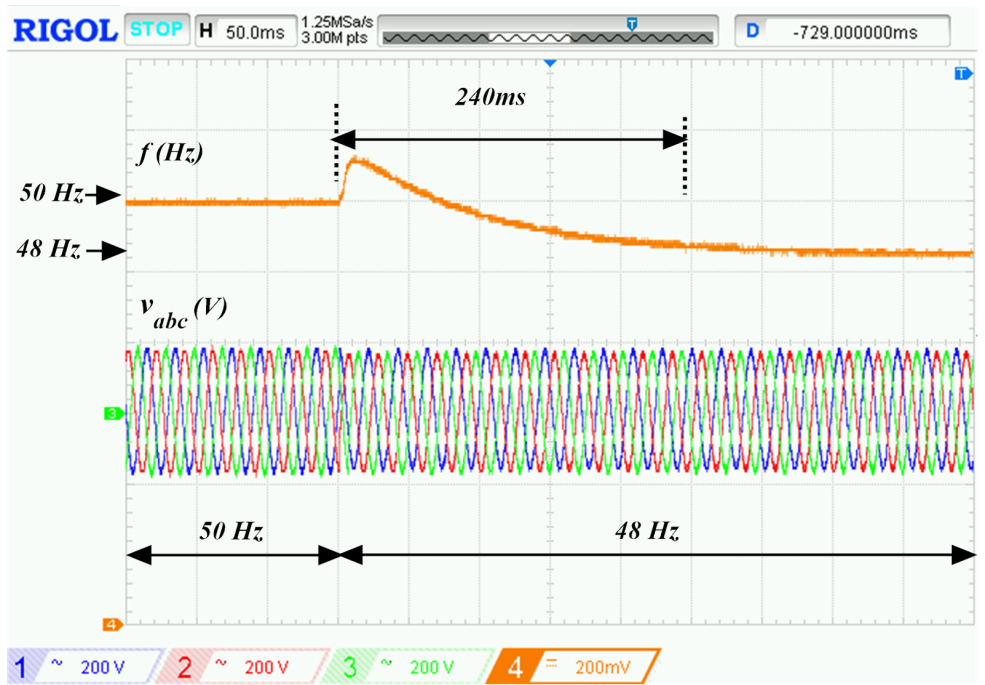

(b) SRF-PLL

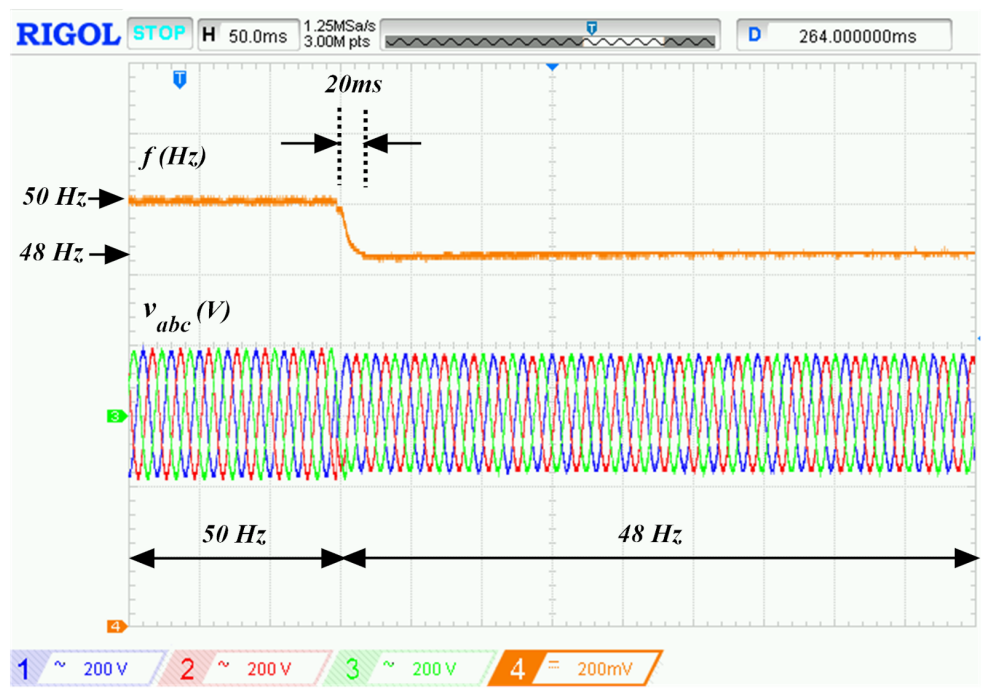

(c) Proposed

Figure 10. Comparative experimental results for a $-2 \mathrm{~Hz}$ frequency step test. 


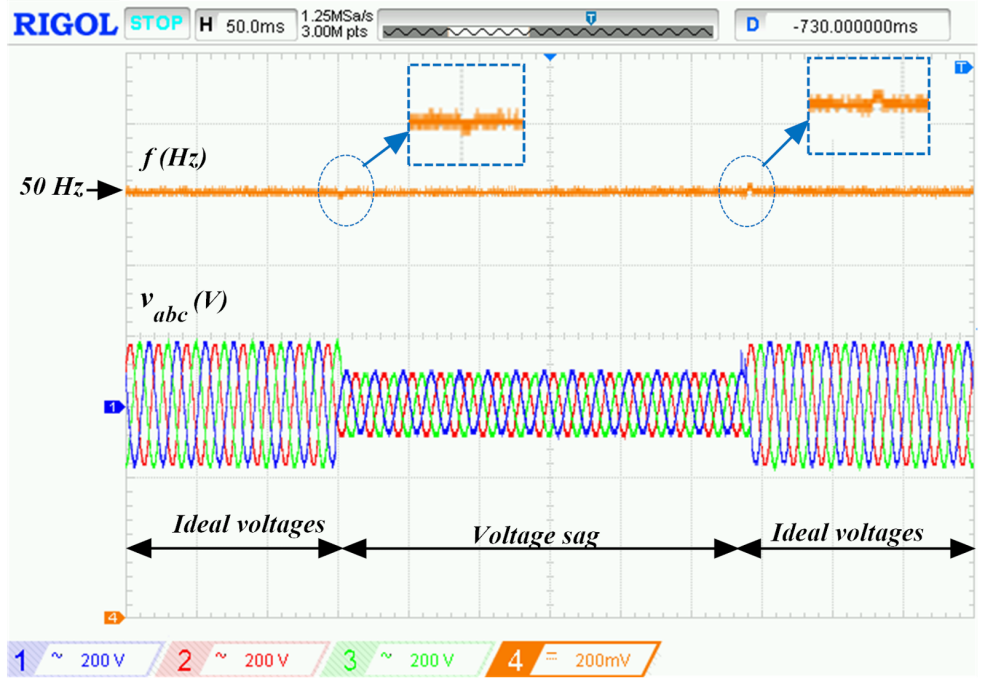

(a) POL

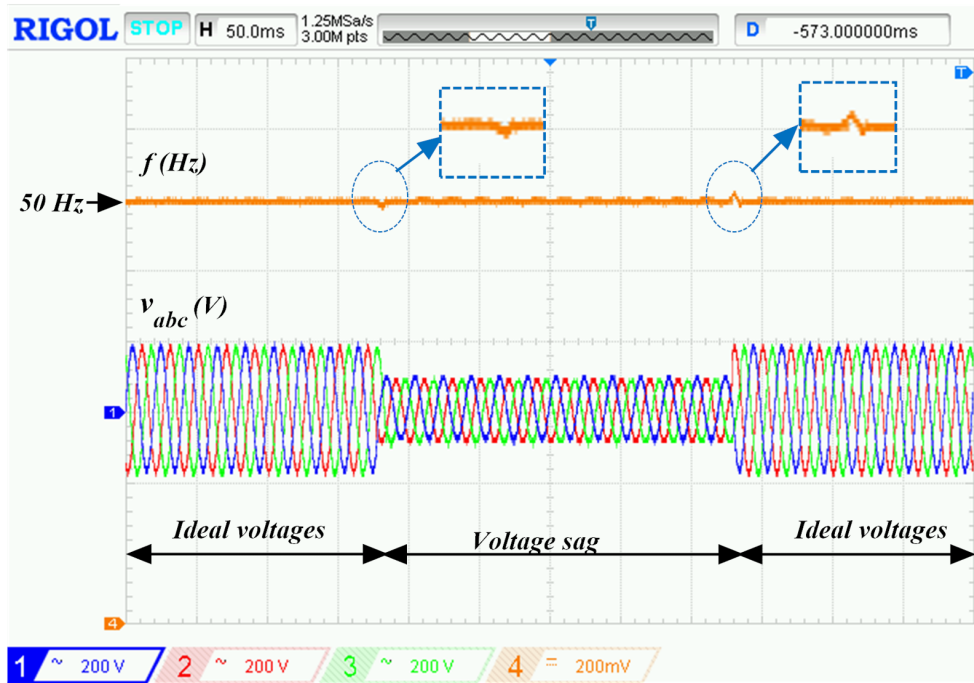

(b) SRF-PLL

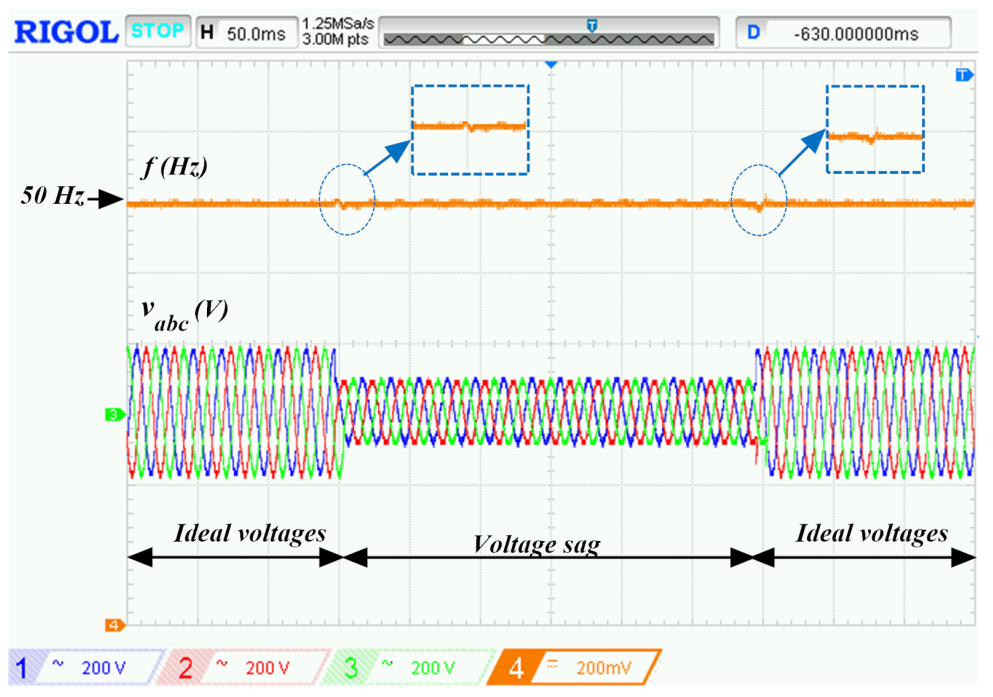

(c) Proposed

Figure 11. Comparative experimental results for a -0.5 p.u. voltage step test. 


\section{Conclusions}

This paper developed a reduced-order generalized integrator-based pseudo open-loop grid-synchronization technique for three-phase system. First, existing implementations of reduced-order generalized integrators are presented. Then a novel structure of reduced-order generalized integrator is presented where the closed-loop poles (both real and imaginary part) are user tunable. This will allow fast dynamic response with desired damping property thanks to the arbitrary pole placement. This is currently unavailable in the literature. To make the novel reduced-order generalized integrator frequency adaptive, an open-loop frequency estimation technique is adapted. This provides frequency estimation with unconditional stability property unlike most of the closed-loop techniques available in the literature. Comprehensive numerical simulation and experimental results are presented with respect to synchronous reference frame PLL and self-tuning filter-based pseudo open-loop grid-synchronization technique. Comparative results demonstrated that the proposed technique is highly accurate and have fast dynamic response at the same time.

Author Contributions: Conceptualization, H.A.; methodology, H.A.; software, H.A.; validation, H.A. and S.B.; formal analysis, H.A.; writing — original draft preparation, H.A.; writing—review and editing, H.A., S.B., E.E. and M.B. All authors have read and agreed to the published version of the manuscript.

Funding: This research received no external funding.

Conflicts of Interest: The authors declare no conflict of interest.

\section{References}

1. Zakzouk, N.E.; Abdelsalam, A.K.; Helal, A.A.; Williams, B.W. High performance single-phase single-stage grid-tied PV current source inverter using cascaded harmonic compensators. Energies 2020, 13, 380. [CrossRef]

2. Islam, S.U.; Zeb, K.; Din, W.U.; Khan, I.; Ishfaq, M.; Hussain, A.; Busarello, T.D.C.; Kim, H.J. Design of robust fuzzy logic controller based on the levenberg marquardt algorithm and fault ride trough strategies for a grid-connected PV system. Electronics 2019, 8, 429. [CrossRef]

3. Safa, A.; Berkouk, E.M.; Messlem, Y.; Gouichiche, A. A robust control algorithm for a multifunctional grid tied inverter to enhance the power quality of a microgrid under unbalanced conditions. Int. J. Electr. Power Energy Syst. 2018, 100, 253-264. [CrossRef]

4. Benali, A.; Khiat, M.; Allaoui, T.; Denai, M. Power Quality Improvement and Low Voltage Ride Through Capability in Hybrid Wind-PV Farms Grid-Connected Using Dynamic Voltage Restorer. IEEE Access 2018, 6, 68634-68648. [CrossRef]

5. Merabet Boulouiha, H.; Khodja, M.; Rahiel, D.; Allali, A.; Kaddour, F.; Denai, M. Power quality enhancement in electricity grids with wind energy using multicell converters and energy storage. J. Renew. Sustain. Energy 2019, 11, 013302. [CrossRef]

6. Merai, M.; Naouar, M.W.; Slama-Belkhodja, I.; Monmasson, E. An adaptive PI controller design for DC-link voltage control of single-phase grid-connected converters. IEEE Trans. Ind. Electron. 2019, 66, 6241-6249. [CrossRef]

7. Hossameldin, A.A.; Abdelsalam, A.K.; Ibrahim, A.A.; Williams, B.W. Enhanced Performance Modified Discontinuous PWM Technique for Three-Phase Z-Source Inverter. Energies 2020, 13, 578. [CrossRef]

8. Lekouaghet, B.; Boukabou, A.; Lourci, N.; Bedrine, K. Control of PV grid connected systems using MPC technique and different inverter configuration models. Electr. Power Syst. Res. 2018, 154, 287-298. [CrossRef]

9. Bayhan, S.; Komurcugil, H. Sliding-Mode Control Strategy for Three-Phase Three-Level T-type Rectifiers with DC Capacitor Voltage Balancing. IEEE Access 2020, 8, 64555-64564. [CrossRef]

10. Rahoui, A.; Bechouche, A.; Seddiki, H.; Abdeslam, D.O. Virtual Flux Estimation for Sensorless Predictive Control of PWM Rectifiers Under Unbalanced and Distorted Grid Conditions. IEEE J. Emerg. Sel. Top. Power Electron. 2020. [CrossRef]

11. Rahoui, A.; Bechouche, A.; Seddiki, H.; Abdeslam, D.O. Grid voltages estimation for three-phase PWM rectifiers control without AC voltage sensors. IEEE Trans. Power Electron. 2018, 33, 859-875. [CrossRef] 
12. Biricik, S.; Komurcugil, H.; Tuyen, N.D.; Basu, M. Protection of Sensitive Loads Using Sliding Mode Controlled Three-Phase DVR With Adaptive Notch Filter. IEEE Trans. Ind. Electron. 2018, 66, 5465-5475. [CrossRef]

13. Biricik, S.; Komurcugil, H. Optimized sliding mode control to maximize existence region for single-phase dynamic voltage restorers. IEEE Trans. Ind. Inform. 2016, 12, 1486-1497. [CrossRef]

14. Ouchen, S.; Steinhart, H.; Benbouzid, M.; Blaabjerg, F. Robust DPC-SVM control strategy for shunt active power filter based on H-Infinity regulators. Int. J. Electr. Power Energy Syst. 2020, 117, 105699. [CrossRef]

15. Ouchen, S.; Betka, A.; Abdeddaim, S.; Menadi, A. Fuzzy-predictive direct power control implementation of a grid connected photovoltaic system, associated with an active power filter. Energy Convers. Manag. 2016, 122, 515-525. [CrossRef]

16. McGrath, B.P.; Holmes, D.G.; Galloway, J.J.H. Power converter line synchronization using a discrete Fourier transform (DFT) based on a variable sample rate. IEEE Trans. Power Electron. 2005, 20, 877-884. [CrossRef]

17. Darwish, H.A.; Fikri, M. Practical considerations for recursive DFT implementation in numerical relays. IEEE Trans. Power Deliv. 2006, 22, 42-49. [CrossRef]

18. Terriche, Y.; Guerrero, J.M.; Vasquez, J.C. Performance improvement of shunt active power filter based on non-linear least-square approach. Electr. Power Syst. Res. 2018, 160, 44-55. [CrossRef]

19. Amirat, Y.; Oubrahim, Z.; Feld, G.; Benbouzid, M. Phasor estimation for power quality monitoring: Least square versus Kalman filter. In Proceedings of the IECON 2017-43rd Annual Conference of the IEEE Industrial Electronics Society, Beijing, China, 29 October-1 November 2017; IEEE: Piscataway, NJ, USA, 2017; pp. 4339-4343.

20. Ahmed, H.; Salgado, I.; Chairez, I.; Benbouzid, M. Robust Gradient Estimator for Unknown Frequency Estimation in Noisy Environment: Application to Grid-Synchronization. IEEE Access 2020, 8, 70693-70702. [CrossRef]

21. Mathuria, K.; Hussain, I.; Singh, B.; Kumar, N. A quadrature oscillator-based DT for accurate estimation of fundamental load current for PV system in distribution network. IEEE Trans. Ind. Inform. 2018, 15, 3324-3333. [CrossRef]

22. Ahmed, H.; Benbouzid, M. Demodulation Type Single-Phase PLL with DC Offset Rejection. Electron. Lett. 2020, 56, 344-347. [CrossRef]

23. Choqueuse, V.; Belouchrani, A.; Auger, F.; Benbouzid, M. Frequency and phasor estimations in three-phase systems: Maximum likelihood algorithms and theoretical performance. IEEE Trans. Smart Grid 2018, 10, 3248-3258. [CrossRef]

24. Radwan, E.; Salih, K.; Awada, E.; Nour, M. Modified phase locked loop for grid connected single phase inverter. Int. J. Electr. Comput. Eng. 2019, 9, 2088-8708. [CrossRef]

25. Chedjara, Z.; Massoum, A.; Massoum, S.; Wira, P.; Safa, A.; Gouichiche, A. A novel robust PLL algorithm applied to the control of a shunt active power filter using a self tuning filter concept. In Proceedings of the 2018 IEEE International Conference on Industrial Technology (ICIT), Lyon, France, 20-22 February 2018; IEEE: Piscataway, NJ, USA, 2018; pp. 1124-1131.

26. Bechouche, A.; Sediki, H.; Abdeslam, D.O.; Haddad, S. An adaptive neural PLL for grid synchronization. In Proceedings of the IECON 2012 - 38th Annual Conference on IEEE Industrial Electronics Society, Montreal, QC, Canada, 25-28 October 2012; IEEE: Piscataway, NJ, USA, 2012; pp. 4451-4456.

27. Meral, M.E.; Çelik, D. Benchmarking simulation and theory of various PLLs produce orthogonal signals under abnormal electric grid conditions. Electr. Eng. 2018, 100, 1805-1817. [CrossRef]

28. Chandramohan, K.; Padmanaban, S.; Kalyanasundaram, R.; Bhaskar, M.S.; Mihet-Popa, L. Grid synchronization of a seven-phase wind electric generator using dq PLL. Energies 2017, 10, 926. [CrossRef]

29. Ahmed, H.; Pay, M.L.; Benbouzid, M.; Amirat, Y.; Elbouchikhi, E. Gain normalized adaptive observer for three-phase system. Int. J. Electr. Power Energy Syst. 2020, 118, 105821. [CrossRef]

30. Ahmed, H.; Amamra, S.; Salgado, I. Fast Estimation of Phase and Frequency for Single Phase Grid Signal. IEEE Trans. Ind. Electron. 2019, 66, 6408-6411. [CrossRef]

31. Ahmed, H.; Benbouzid, M.; Ahsan, M.; Albarbar, A.; Shahjalal, M. Frequency Adaptive Parameter Estimation of Unbalanced and Distorted Power Grid. IEEE Access 2020, 8, 8512-8519. [CrossRef]

32. Ngo, T.; Biricik, S.; Basu, M. A Self-tuning Grid Synchronization Method for Active Power Filters. Electr. Power Compon. Syst. 2016, 44, 1947-1957. [CrossRef] 
33. Biricik, S.; Redif, S.; Özerdem, Ö.C.; Khadem, S.K.; Basu, M. Real-time control of shunt active power filter under distorted grid voltage and unbalanced load condition using self-tuning filter. IET Power Electron. 2014, 7, 1895-1905. [CrossRef]

34. Girgis, A.A.; Hwang, T.D. Optimal estimation of voltage phasors and frequency deviation using linear and non-linear Kalman filtering: Theory and limitations. IEEE Trans. Power Appar. Syst. 1984, 2943-2951, doi:10.1109/TPAS.1984.318297. [CrossRef]

35. Amirat, Y.; Oubrahim, Z.; Ahmed, H.; Benbouzid, M.; Wang, T. Phasor Estimation for Grid Power Monitoring: Least Square vs. Linear Kalman Filter. Energies 2020, 13, 2456. [CrossRef]

36. Kherbachi, A.; Chouder, A.; Bendib, A.; Kara, K.; Barkat, S. Enhanced structure of second-order generalized integrator frequency-locked loop suitable for DC-offset rejection in single-phase systems. Electr. Power Syst. Res. 2019, 170, 348-357. [CrossRef]

37. Bendib, A.; Chouder, A.; Kara, K.; Kherbachi, A.; Barkat, S. SOGI-FLL Based Optimal Current Control Scheme for Single-Phase Grid-Connected Photovoltaic VSIs with LCL Filter. In Proceedings of the 2018 International Conference on Electrical Sciences and Technologies in Maghreb (CISTEM), Algiers, Algeria, 28-31 October 2018; IEEE: Piscataway, NJ, USA, 2018; pp. 1-6.

38. Bendib, A.; Chouder, A.; Kara, K.; Kherbachi, A.; Barkat, S.; Issa, W. New modeling approach of secondary control layer for autonomous single-phase microgrids. J. Frankl. Inst. 2019, 356, 6842-6874. [CrossRef]

39. Mekhilef, S.; Tarek, M.; Abd. Rahim, N. Single-phase hybrid active power filter with adaptive notch filter for harmonic current estimation. IETE J. Res. 2011, 57, 20-28. [CrossRef]

40. Teke, A.; Meral, M.E.; Cuma, M.U.; Tümay, M.; Bayindir, K.Ç. OPEN unified power quality conditioner with control based on enhanced phase locked loop. IET Gener. Transm. Distrib. 2013, 7, 254-264. [CrossRef]

41. Ahmed, H.; Amamra, S.A.; Bierhoff, M. Frequency-Locked Loop Based Estimation of Single-Phase Grid Voltage Parameters. IEEE Trans. Ind. Electron. 2019, 66, 8856-8859. [CrossRef]

42. Pay, M.L.; Ahmed, H. Modeling and Tuning of Circular Limit Cycle Oscillator FLL With Preloop Filter. IEEE Trans. Ind. Electron. 2019, 66, 9632-9635. [CrossRef]

43. Ahmed, H.; Bierhoff, M.; Benbouzid, M. Multiple Nonlinear Harmonic Oscillator-Based Frequency Estimation for Distorted Grid Voltage. IEEE Trans. Instrum. Meas. 2020, 69, 2817-2825. [CrossRef]

44. Verma, A.K.; Jarial, R.K.; Roncero-Sanchez, P.; Ungarala, M.R.; Guerrero, J.M. An Improved Hybrid Pre-Filtered Open-Loop Algorithm For Three-Phase Grid Synchronization. IEEE Trans. Ind. Electron. 2020. [CrossRef]

45. Terriche, Y.; Mutarraf, M.U.; Mehrzadi, M.; Lashab, A.; Guerrero, J.M.; Vasquez, J.C.; Kerdoun, D. Adaptive CDSC-Based Open-Loop Synchronization Technique for Dynamic Response Enhancement of Active Power Filters. IEEE Access 2019, 7, 96743-96752. [CrossRef]

46. Safa, A.; Berkouk, E.M.; Messlem, Y.; Chedjara, Z.; Gouichiche, A. A Pseudo Open Loop Synchronization technique for heavily distorted grid voltage. Electr. Power Syst. Res. 2018, 158, 136-146. [CrossRef]

47. Teodorescu, R.; Liserre, M.; Rodriguez, P. Grid Converters for Photovoltaic and Wind Power Systems; John Wiley \& Sons: Hoboken, NJ, USA, 2011; Volume 29.

48. Busada, C.A.; Jorge, S.G.; Leon, A.E.; Solsona, J.A. Current controller based on reduced order generalized integrators for distributed generation systems. IEEE Trans. Ind. Electron. 2011, 59, 2898-2909. [CrossRef]

49. Ahmed, H.; Benbouzid, M. Simplified Second-Order Generalized Integrator-Frequency-Locked Loop. Adv. Electr. Electron. Eng. 2019, 17, 405-412. [CrossRef]

(C) 2020 by the authors. Licensee MDPI, Basel, Switzerland. This article is an open access article distributed under the terms and conditions of the Creative Commons Attribution (CC BY) license (http://creativecommons.org/licenses/by/4.0/). 